\title{
How Alexander von Humboldt's life story can inspire innovative soil research in developing countries
}

\author{
Johan Bouma ${ }^{1, *, * *}$ \\ ${ }^{1}$ Wageningen University, Wageningen, the Netherlands \\ retired \\ ** Invited contribution by Johan Bouma, recipient of the EGU Alexander von Humboldt Medal 2017. \\ Correspondence to: Johan Bouma (johan.bouma@planet.nl)
}

Received: 29 April 2017 - Discussion started: 13 June 2017

Revised: 16 August 2017 - Accepted: 21 August 2017 - Published: 13 September 2017

\begin{abstract}
The pioneering vision of Alexander von Humboldt of science and society of the early 1800s is still highly relevant today. His open mind and urge to make many measurements characterizing the "interconnected web of life" are crucial ingredients as we now face the worldwide challenge of the UN Sustainable Development Goals. Case studies in the Philippines, Vietnam, Kenya, Niger, and Costa Rica demonstrate, in Alexander's spirit, interaction with stakeholders and attention to unique local conditions, applying modern measurement and modeling methods and allowing inter- and transdisciplinary research approaches. But relations between science and society are increasingly problematic, partly as a result of the information revolution and "post-truth", "fact-free" thinking. Overly regulated and financially restricted scientific communities in so-called developed countries may stifle intellectual creativity. Researchers in developing countries are urged to "leapfrog" these problems in the spirit of Alexander von Humboldt as they further develop their scientific communities. Six suggestions to the science community are made with particular attention to soil science. (The Humboldt lecture, presented by the 2017 recipient of the Alexander von Humboldt lecture, Johan Bouma, can be accessed at http://client.cntv.at/egu2017/ml1.)
\end{abstract}

\section{Introduction}

The scientific career of Alexander von Humboldt, a name linked with the medal for research in developing countries by the European Geosciences Union, is highly inspiring for scientists operating in the current scientific arena as one realizes after reading the impressive biography by Andrea Wulf (2015). He was the first in the early 1800 s to emphasize the importance of the "interconnected web of life" rather than isolated disciplinary and taxonomic issues as was the custom at the time and still is in some quarters. He saw man as part of nature rather than as its justified and exclusive consumer, the dominant view at the time and still prevalent today. It is now generally accepted that the geosciences are not only closely linked with other environmental sciences but with society itself. Modern measuring, sensing, and modeling facilities now offer the possibility to express ecosystem dynamics in quantitative terms rather than in terms of the flowery illustrated books, reports, letters, and drawings by von Humboldt, but the basic message is the same. But perhaps his greatest contribution has been his enthusiastic and uncompromising dedication to be receptive to new ideas ("keep learning") and to maintain an open, inquisitive mind when observing phenomena in nature or when interacting with land users in Latin America and the United States. He always encouraged young colleagues and shared his data freely. As a scientist he carried his instruments everywhere, meticulously documenting his many observations to be systematically analyzed later, often deep into the night. At the same time he was in dialogue with poets like Goethe, quite aware that facts are experienced differently by different people, as the experience involves personal emotions and values. Two centuries before terms like inter- and transdisciplinarity were coined, they were acted out in real life by von Humboldt as, for example, he observed 
the misery of farmers in the Aragua valley in the Andes following erosion and soil degradation as a side effect of cutting upland forests. In general he warned against developments where science may feed the brain with abstract data while ignoring imagination in the process: a message with high relevance for the current scientific arena.

The relation between science and society has dramatically changed in the early 21 st century and has become problematic not only in the so-called developed world but also globally as the internet reaches all corners of the world, mobile phones are used everywhere, and social media are prominent in daily life (e.g., Kahan, 2015; Bouma, 2015). "Citizen science" is promoted while many see science as providing only yet another opinion. The terms "post-truth", "fact free", and "alternative facts" have become prominent in public debate. Effects differ among scientific disciplines but issues develop, in particular, in land-related environmental and food science addressing concerns in the everyday lives of citizens. On the other side of the fence, governmental funding of environmental research is decreasing in many countries and researchers are increasingly forced to generate research contracts with industrial or commercial partners. Ever larger numbers of students follow tight curricula that leave limited time for side activities and scientific workers are being judged and squeezed by tight performance indicators where publication requirements figure prominently. The emphasis on publishing in, preferably, internationally refereed journals has resulted in an explosion of the number of new journals and a structural lack of competent referees (e.g., Munafo et al., 2017). As disciplinary papers, developing yet another new technique or introducing yet another new model, are relatively rapid to generate, very much needed time-consuming inter- and transdisciplinary approaches suffer. There are, in short, reasons for concern.

All these developments are of particular concern to researchers in so-called developing countries. They often do not have the facilities or equipment to generate papers that are acceptable to the big journals, restricting their professional development, while they perform good research in many cases. How to proceed? Are we not all, in fact, developing countries though development may move in opposite directions in different countries?

Considering these observations, the objectives of this paper are to briefly review and analyze work done by our group in developing countries and discuss how what appear to be unfavorable developments in science-society relations in so-called developed countries can be avoided in developing countries. How can they possibly "leapfrog" to a more stimulating, productive, less stressful, and sustainable condition in the spirit of Alexander von Humboldt? Attention will be confined to the soil science discipline, which is an essential part of environmental sciences.

\section{Examples of eco-regional research in developing countries}

Work by the former chair group Soil Inventarisation and Land Evaluation of Wageningen University in the Philippines, Vietnam, Kenya, Niger, and Costa Rica and projects executed in the context of the Ecoregional Methodology Fund will be briefly reviewed with reference to source publications, with the intention of reflecting and documenting the background of the 2017 von Humboldt medal. Certainly, many other reports and papers on research in developing countries have been written in the von Humboldt spirit.

\subsection{Growing rice in the Philippines}

Rice is the main food source in Southeast Asia and in approximately $75 \%$ of the area, irrigation is used to submerge the growing rice plants with water on top of a slowly permeable puddled layer of topsoil. To produce $1 \mathrm{~kg}$ of rice, $5000 \mathrm{~L}$ of water are needed, and because fresh water is scarce in many areas, understanding soil water regimes is crucial to define optimal irrigation regimes intended to save water. Wopereis et al. (1994) developed a field test to measure infiltration rates through the puddled surface layer of soil, and this value varied significantly in different soils, following different puddling practices that could be refined based on such measurements. Statistical techniques were used to estimate the minimum number of samples needed (Wopereis et al., 1992, 1993). Rice is also grown without irrigation, and then natural soil moisture regimes determine development of the rice plants. Here, bypass flow (which is rapid downward movement of water and solutes beyond the root zone along air-filled cracks in the soil) is an important process that cannot be characterized with existing physical flow theory that implicitly assumes soils to be homogeneous. The application of a new technique to measure bypass flow allowed the development of innovative soil management procedures, restricting the potential for bypass flow by modifying surface structure and crack continuity (Wopereis et al., 1994). Data obtained were extended to Tarlac province (300 $000 \mathrm{ha}$ ) for a regional analysis, predicting rice yields with the newly developed simulation model ORYZA as a function of soil differences and management practices. Stein et al. (1988) applied geostatistics to interpolate from points to areas using units of the soil map as a basis for sample stratification. It allows one to optimally use uniformity in soil units, in particular in terms of spatial variability of the soil variables. In this way the study contributes to collect information more efficiently and run simulation models in a more parsimonious way with quantitative uncertainty.

\subsection{Managing acid sulfate soils in Vietnam}

A major program in Vietnam by van Mensvoort, le Quang Tri, le Quang Minh, and Husson, in close cooperation with 
Can Tho University, focused on the agricultural use of acid sulfate soils (Minh et al., 1997a, b; Husson et al., 2000a, b). These soils occur in marine deposits near the sea, containing pyrite that upon aeration and oxidation can result in strong acidification making soils unfit for plant growth. Chemical processes have been well documented in literature, but local implications for land and water management remained undefined. In Vietnam alone, there are 2 million ha of these soils occur, 12 million ha occur in the world overall. As long as the pyrite-containing soil layers are submerged nothing happens and soils can be highly productive. Properly managing water regimes is therefore of crucial importance to avoid aeration and oxidation of pyrite-containing layers and as local soil and hydrological conditions vary significantly over short distances, it is impossible to devise generalized modeling procedures. Farmers' experience, assisted by local measurements and observations, therefore played a key role when defining the appropriate management by digging ditches and heightening soil surfaces in between. Depending on soil conditions, different system dimensions were developed in three key areas. When vertical cracks form as soils dry out, the effects of bypass flow on acidification can be significant as was demonstrated by bypass measurements. Deeply penetrating cracks cause rapid acidification at much greater depth than in homogeneous soil. Next, bypass flow results in rapid leaching of highly acidic water (Minh et al., 1997c).

\subsection{Integrated nutrient management in Africa}

A major problem of African agriculture is the negative soil nutrient balance: more nutrients are extracted than supplied. Smaling et al. (1992) developed a framework for integrated nutrient management in the tropics, presenting Kenya as a case study and showing significant differences among regions and soils. He successfully continued the development of the QUEFTS model relating natural fertility and fertilization rates to nutrient uptake and crop yields, allowing the assessment of local potentials and limitations (Smaling and Janssen, 1993). Bypass flow was prominent in wellstructured clay soils (Vertisols), leading to a loss of surfaceapplied nutrients of up to $60 \%$. Also, the evaporation of nitrogen compounds in these high-pH soils contributed to losses. Reductions could be achieved by modifying surface structures (Smaling and Bouma, 1992). The interdisciplinary approach of this work was emphasized by investigating the effects of parasitic weeds on crop yields (Smaling et al., 1991).

\subsection{Agricultural development in the Sahelian region in Africa (Niger)}

The arid Sahelian region in west Africa is particularly vulnerable in terms of agricultural productivity, not only because of the low natural fertility of sandy soils but also because of low and erratic rainfall that is expected to become even more problematic in future due to climate change. Brouwer and Bouma (1997), Gandah et al. (2003), and Brouwer (2008) studied farming systems in Niger in a comparable manner to the work in Vietnam by focusing on farmers' management practices when trying to cope with the severe constraints on farming. Theoretical studies on potential crop yields, assuming optimal water and nutrient availability, are irrelevant in an extremely poor country like Niger with limited agricultural policies, where farmers cannot afford fertilizers, and with no water for irrigation in agricultural land. Impressive ways of coping that have been developed by farmers include corraling cattle to gather manure that is spread over the land, leaving crop residues on the land, and growing crops near certain tree species or abandoned termite mounds where fertility is higher and competition for water limited. A scoring technique was introduced to allow reliable estimates of crop yields that had a very high spatial variability even within fields (with a factor up to 30), and this was quantified with statistical techniques, showing strong negative relations of yields with distances to settlements (Stein et al., 1997) or with a lack of shrubs (Van Groenigen et al., 2000). The research showed that corraling the cattle at night was effective for collecting manure, but application rates to the land, varying in practice from 3 to $17 \mathrm{tha}^{-1}$, were often considerably higher than a threshold value of $3 \mathrm{tha}^{-1}$ that was developed in the program (Brouwer and Powell, 1998; Gandah et al., 2003). Higher values result in the leaching of nutrients during rain in these highly permeable sandy soils. The locally developed tesse system, where plants are grown in individual small pits filled with fertilized soil, is effective but highly labor intensive. Studies also showed that surface sealing and runoff was a dominant process in areas farther away from settlements, explaining the results of a statistical analysis showing a higher effect of water shortages as compared with nutrient shortages (Gaze et al., 1997). Surface sealing and low infiltration rates were particularly prominent because of the addition of windblown silt particles, filling the pore spaces between the sand grains.

\subsection{Soil-related land use patterns in Costa Rica}

After studying land use in Costa Rica with remote sensing combined with extensive field work, Huising et al. (1994) introduced the concept of land use zones (LUZs) in the Guacimo region of $900 \mathrm{~km}^{2}$ defining large geographic units with particular land use patterns and dynamic behavior. Applying this concept, the study indicated that soils in $18 \%$ of the area were overused, leading to degradation processes, while in $50 \%$ of the soils, more intensive management practices would be feasible, providing a guide for regional land use policies. Studies in banana fincas showed that soil differences could explain $67 \%$ of the yield variation (Veldkamp et al., 1990). Soil moisture regimes could be related to nematode development (Stoorvogel et al., 1999). Stoorvogel et al. (1999) also developed innovative soil databases, based on 
soil surveys incorporated in Geographical Information Systems (GISs), based on a functional approach, in this case in terms of the risk of pesticide leaching. This way, simulation models of crop growth and nutrient regimes could logically be linked with the GIS system, strongly increasing its applicability, as was demonstrated when developing alternative land use systems for the Neguev area in Costa Rica and banana fincas (e.g., Stoorvogel et al., 2004). Comparing the behavior of young volcanic soils (Andosols) with old ones (Ultisols) showed that the former had a higher resilience as shown by a better recovery of soil structure after compaction following deforestation practices (Spaans et al., 1989, 1990). Recovery was a result of a higher biological activity.

\subsection{The eco-regional methodology program}

In addition to the above activities, considerable attention has been paid to coordinate and actively participate in an Ecoregional Methodology Program funded by the Dutch Government, as summarized in Bouma et al. (2007). Taking the policy cycle as a guiding principle, studies were made on (i) land use change in the Kenyan Highlands; (ii) the effects of trade liberalization in Peru; (iii) water resources on the Tibetan Plateau; (iv) land use problems and conflicts in the Philippines; (v) effects of environmental conditions on human health in Ecuador; (vi) soil erosion in the Kenyan Highlands, and (vii) reestablishing bank credits to be received by farmers in the Highveld region of South Africa.

\section{Learning from developed countries when relating soil science to society: possibilities for leapfrogging?}

As soil scientists we should not forget how our profession was established by people like Dukochaev in Russia and Marbut in the USA, who traveled widely in the late 19th century observing different soils in different landscapes, in a manner that resembles the endeavors of Alexander von Humboldt. Like Alexander, they saw something that others before them had not seen: then as well as now the very key to progress in science. Soil turned out to be more than "dirt obscuring rocks". Researchers in developing countries would be well advised to take note of developments in the so-called developed world and work actively to define ways and means to avoid problems encountered elsewhere, taking advantage of many available studies (e.g., World Bank, 2008; Rockström et al., 2009, 2010; IFAD, 2011; Schwilch et al., 2012; Lal, 2013; Bouma et al., 2014; FAO \& ITPS, 2015; van Ittersum et al., 2016). The following six points are intended to stimulate discussions on future soil research that may also be relevant for other scientific disciplines:

\subsection{Define clear goals}

The amount of basic soil data in information systems, the number of available methods and models and continuous streams of monitoring data present an overwhelming challenge to the 21 st-century soil scientist. Without clear goals, only trees will be seen, while the forest is obscured. Sustainable development is an excellent overall goal and the 17 Sustainable Development Goals (SDGs), defined by the UN and approved by all its members at the General Assembly in September 2015, are excellent aims (e.g., Bouma, 2014, 2016; Keesstra et al., 2016; Bouma and Montanarella, 2016) as is the 4 per 1000 proposal, accepted at the Paris Climate conference also in 2015 and focused on increasing the percentage of carbon in soils as a climate change mitigation measure.

\subsection{Adhere strictly to scientific principles}

The scientific method, when followed, does not produce just another opinion. Define the problem; reframe it in terms of an objective that can be researched; formulate a hypothesis to be tested, choose methods and procedures that have proven their reliability and reproducibility in previous research or develop new methods if needed. Make an adequate number of measurements in adequate number to allow the statistical expression of results in terms of reliability and accuracy and pay attention to the way results are communicated. Also, show a base level of hypothetical results when no or highly simplified soil data are applied. Only then can the effect and importance of using appropriate soil data be illustrated.

\subsection{Engage stakeholders but stay in charge}

The need to engage stakeholders and policy makers in transdisciplinary research has been acknowledged widely but the question still lingers of how to best do it. My suggestion: try the step-by-step approach (Hoosbeek and Bryant, 1992; Bouma, 1997, Bouma et al., 2008). In summary: stakeholder knowledge is empirical and qualitative in nature. As scientists get involved, presented procedures become more quantitative and underlying mechanisms can be better explained. From discussions with stakeholders, the conclusion can be reached that their knowledge is inadequate to solve the problem that has been identified or, better, the discussions may lead to the intended goal being reached. Next, relatively simple and available techniques are tested. If they yield satisfactory results, then the project can be terminated. If not, more elaborate techniques are needed and new methods may need to be developed. Costs will increase step by step and the ultimate project design will be the result of a cost-benefit analysis. This approach has a number of advantages.

i. Stakeholders are taken along on a "scientific journey" involving joint learning and increasingly shared ownership. Stakeholders are shown that they are taken seri- 
ously by not being "talked-down" to (by the "elite"), the latter a major reason for the science-society divide and "fact-free" and "post-truth" attitudes.

ii. Many problems can be solved by applying existing data and methods, not needing new research. Bouma et al. (2015) showed six examples of research programs, three of which could be completed without developing new methods. But in three cases new basic research was needed and this was documented providing a rational argument for new research. Not having fancy equipment and supercomputers does not necessarily imply that effective research cannot be realized.

iii. The scientific method applies to all knowledge levels, ranging from empirical to mechanistic and from qualitative to quantitative.

\subsection{Avoid atomization of soil science and associate with physical geographers}

When interacting with other disciplines, stakeholders, and policy makers, soil science is more effective when the various subdisciplines work together rather than separately. The following sequence may be adhered to: start with pedology, defining the physical constitution of a dynamic soil in a landscape context; next add hydrology, chemistry, and biology in that particular sequence. When this sequence is not followed, the potential of soil science contributions to interdisciplinary research may not be reached. Physical geographers are not only a good source of spatial landscape data, but they also are experts in defining soil-landscape relations.

\subsection{Develop storylines to facilitate communication}

Soil research as presented in scientific papers or reports often makes an isolated, clinical impression. Putting research in a storyline context is quite useful for improving communication. Addressing the SDGs is one way; another is to express the work in the DPSIR scheme, defining drivers, pressures, state, impacts, and responses of external effects on land use (Van Camp et al., 2004; Bouma et al., 2008). Realizing that different stakeholder or policy groups have different goals, based on their particular perceptions of the truth, a range of scenarios can be formulated that do justice to each of these perceptions. The key premise in all of this should be that anything can be done anywhere. The scientific analysis will show what the likely economic, social, and environmental consequences are of each scenario.The stakeholders and the politicians decide by choosing the ultimate scenario, not the scientist.

\subsection{Preserve intellectual vigor}

Make sure that regulations, guidelines, indicators, and judgement criteria for research and researchers do not become too restricting leading to a routine, all too pragmatic, and risk-averse attitude of researchers. Initiate long-duration programs, allowing continued interaction with stakeholders when preparing, executing, and implementing research. Actively engage agronomists, hydrologists, ecologists, and climatologists in a proactive manner in joint programs focusing on SDGs. Judge researchers on their main papers not only on the number of papers or citations. Create conditions where research is fun rather than a burden. The education of young scientists is important, and innovative educational approaches are important and deserve to be followed widely (e.g., Field et al., 2011, 2013; Jarvis et al., 2012; Hartemink et al., 2014). And, finally, all soil science students should read the biography of Alexander von Humboldt as a source of inspiration.

As their scientific network is being established, researchers and policy makers in developing countries would be well advised to take these signals seriously and apply them to establishing vital scientific regimes. And, above all, look to Alexander von Humboldt as an inspiring example as to what science in the real world can be all about.

Data availability. No data sets were used in this article.

Competing interests. The author declares that he has no conflict of interest.

Acknowledgements. Thanks to our PhD students: Marco Wopereis, Tini van Mensvoort, le Quang Tri, le Qung Minh, Olivier Husson, Eric Smaling, Mohamadou Gandah, Jeroen Huising, and Jetse Stoorvogel. Thanks to the $\mathrm{PhD}$ (co-)supervisors: Martin Kropff, Vo Tong Xuan, To PhucTuong, Louise Fresco, Eric Smaling, Joost Brouwer, Niek van Duivenbooden, Alfred Stein, and Martin Moolenaar. Contributions by the Ecoregional Development Fund are also gratefully acknowledged: Rudy Rabbinge, Roberto Quiroz, Mario Herrera, Stephen Staal, Water Immerzeel, Raymund Roetter, Geert Sterk, Jetse Stoorvogel, Rick van den Bosch, Patrick Gichera, and Fred Muchena. Contributions by Damien Field are gratefully acknowledged.

Edited by: Boris Jansen

Reviewed by: Peter Finke and Jozef Deckers

\section{References}

Bouma, J.: Role of quantitative approaches in soil science when interacting with stakeholders, Geoderma, 78, 1-12, 1997.

Bouma, J.: Soil science contributions towards Sustainable Development Goals and their implementation: linking soil functions with ecosystem services, J. Plant Nutr. Soil Sc., 177, 111-120, 2014.

Bouma, J.: Engaging soil science in transdisciplinary research facing wicked problems in the information society, Soil Sci. Soc. 
Am. J., 79, 454-458, https://doi.org/10.2136/sssaj2014.11.0470, 2015.

Bouma, J.: Hydropedology and the societal challenge of realizing the 2015 United Nations Sustainable Development Goals, Vadose Zone J., 15, 36-48, https://doi.org/10.2136/vzj2016.09.0080, 2016.

Bouma, J. and Montanarella, L.: Facing policy challenges with inter- and transdisciplinary soil research focused on the UN Sustainable Development Goals, SOIL, 2, 135-145, https://doi.org/10.5194/soil-2-135-2016, 2016.

Bouma, J., Stoorvogel, J. J., Quiroz, R., Staal, S., Herrero, M., Immerzeel, W., Roetter, R. P., van den Bosch, H., Sterk, G., Rabbinge, R., and Chater, S.: Ecoregional Research for Development, Adv. Agron., 93, 257-311, 2007.

Bouma, J., de Vos, J. A., Sonneveld, M. P. W., Heuvelink, G. B. M., and Stoorvogel, J. J.: The role of scientists in multiscale land use analysis: lessons learned from Dutch communities of practice, Adv. Agron., 97, 177-239, 2008.

Bouma, J., Batjes, N., Sonneveld, M. P. W., and Bindraban, P.: Enhancing soil security for smallholder agriculture, in: Soil management of smallholder agriculture, Advances in Soil Science, edited by: Lal, R. and Stewart, B. A., CRC Press, Baco Raton (FL), 17-37, 2014.

Bouma, J., Kwakernaak, C., Bonfante, A., Stoorvogel, J. J., and Dekker, L. W.: Soil science input in Transdisciplinary projects in the Netherlands and Italy, Geoderma Regional, 5, 96-105, https://doi.org/10.1016/j.geodrs.2015.04.002, 2015.

Brouwer, J.: The importance of within-field soil and crop growth variability to improving food production in a changing Sahel. A summary in images based on five years of research at ICRISAT Sahelian Center, Niamey, Niger. IUCN Commission on Ecosystem Management, Gland, Switzerland, 12 pp., available at: http://cmsdata.iucn.org/downloads/cem_ csd_16_brochure_sahel_hq.pdf (last access: 12 May 2017), 2008.

Brouwer, J. and Bouma, J.: Soil and crop growth variability in the Sahel, Infor. Bull. 49, ICRISAT-Sahelian Center and Agric. Univ. Wageningen Neth., Patencheru 502324, Andhra Pradesh, India, 1997.

Brouwer, J. and Powell, J. M.: Microtopography and leaching: possibilities for making more efficient use of nutrients in African agriculture, in: Nutrient Balances as Indicators of Productivity and Sustainability in sub-Saharan African Agriculture, edited by: Smaling, E. M. A., Agr. Ecosyst. Environ., 71, 229-239, 1998.

FAO \& ITPS: Status of the World's Soil Resources. Main Report, FAO and Intergovernmental Technical Panel (ITPS), Rome, Italy, 2015.

Field, D. J., Koppi, A. J., Jarrett, L. A., Abbott, L. K., Cattle, S. R., Grant, C. D., McBratney, A. B., Menzies, N. W., and Weatherley, A. J.: Soil Science teaching principles, Geoderma, 167/168, 914, 2011.

Field, D. J., Koppi, A. J., Jarrett, L., and McBratney, A. B.: Engaging employers, graduates and students to inform the future curriculum needs of soil science, 19th Australian Conference on Science and Mathematics Education, 19-21 September 2013, Canberra, Australia, 2013.

Gandah, M., Bouma, J., Brouwer, J., Hiernaux, P., and van Duivenbooden, N.: Strategies to optimize allocation of limited nutrients to sandy soils of the Sahel: a case study from Niger, West Africa, Agr. Ecosyst. Environ., 94, 311-319, 2003.

Gaze, S. R., Simmonds, L. P., Brouwer, J., and Bouma, J.: Measurement of surface redistribution of rainfall and modeling its effect on water balance calculations for a millet field on sandy loam soil in Niger, J. Hydrol., 188/189, 267-284, 1997.

Hartemink, A. E., Balks, M. B., Chen, Z.-S., Drohan, P., Field, D. J., Krasilnikov, P., Lowe, D. J., Rabenhorst, M., van Rees, K., Schad, P., Schipper, L. A., Sonneveld, M., and Walter, C.: The joy of teaching soil science, Geoderma, 217-18, 1-9, 2014.

Hoosbeek, M. R. and Bryant, R. B.: Towards the quantitative modelling of pedogenesis - a review, Geoderma, 55, 183-210, 1992.

Huising, E. J., Wielemaker, W. G., and Bouma, J.: Evaluating land use at the sub-regional level in the Atlantic zone of Costa Rica, considering biophysical land potentials, Soil Use and Management, 10, 152-158, 1994.

Husson, O., Hanhart, K., Phung, M. T., and Bouma, J.: Water management for rice cultivation on acid sulphate soils in the Plain of Reeds, Vietnam, Agr. Water Manage., 46, 91-109, 2000a.

Husson, O., Phung, M. T., and Van Mensvoort, M. E. F.: Soil and water indicators for optimal practices when reclaiming acid sulphate soils in the Plain of Reeds, Viet Nam, Agr. Water Manage., 45, 127-143, 2000b.

IFAD: Rural Poverty Report: New Realities, New Challenges: New Opportunities for tomorrow's generation, Rome, Italy, 2011.

Jarvis, H. D., Collett, R., Wingenbach, G., Heilman, J. L., and Fowler, D.: Developing a Foundation for Constructing New Curricula in Soil, Crop and Turfgrass Sciences, Journal of Natural Resources \& Life Sciences, 41, 7-14, 2012.

Kahan, D. M.: What is the Science of:"Science Communication"?, Journal of Science Communication, 14, 1-10, 2015.

Keesstra, S. D., Bouma, J., Wallinga, J., Tittonell, P., Smith, P., Cerdà, A., Montanarella, L., Quinton, J. N., Pachepsky, Y., van der Putten, W. H., Bardgett, R. D., Moolenaar, S., Mol, G., Jansen, B., and Fresco, L. O.: The significance of soils and soil science towards realization of the United Nations Sustainable Development Goals, SOIL, 2, 111-128, https://doi.org/10.5194/soil-2-111-2016, 2016.

Lal, R.: Food security in a changing climate, Ecohydrology \& Hydrobiology, 13, 8-21, 2013.

Minh, L. Q., Tuong, T. P., van Mensvoort, M. E. F., and Bouma, J.: Contamination of surface water as affected by land use in acid sulphate soils in the Mekong River Delta, Vietnam, Agr. Ecosyst. Environ., 61, 19-27, 1997a.

Minh, L. Q., Tuong, T. P., van Mensvoort, M. E. F., and Bouma, J.: Tillage and water management for riceland productivity in acid sulphate soils of the Mekong Delta, Vietnam, Soil Till. Res., 42, 1-14, 1997b.

Minh, L. Q., Tuong, T. P., Booltink, H. W. G., van Mensvoort, M. E. F., and Bouma, J.: Bypass flow and its role in leaching of raised beds under different land use types on an acid sulphate soil, Agr. Water Manage., 32, 131-147, 1997c.

Munafo, M., Nosek, B. A., Bishop, D. V. M., Button, K. S., Chambers, C. O., Percie du Sert, N., Simonsohn, U., Wagenmakers, E. J., de Ware, J. J., and Ionnidis, J. P. A.: A manofesto for reproducible science, Nature Human Behaviour, 1, 0021, https://doi.org/10.1038/s41562-016-0021, 2017.

Rockström, J., Steffen, W., Noone, K., Persson, A., Chapin III, F. S., Lambin, E., Lenton, T. M., Scheffer, M., Folke, C., Schellnhu- 
ber, H. J., Nykvist, B., de Wit, C. A., Hughes, T., van der Leeuw, S., Rodhe, H., Sorlin, S., Snyder, P. K., Constanza, R., Svedin, U., Falkenmark, M., Karlberg, L., Correll, R. W., Fabbry, V. J., Hansen, J., Walker, B., Liverman, D., Richardson, K., Crutzen, P., and Foley, J.: Planetary boundaries: exploring the safe operating space for humanity, Ecol. Soc., 14, 32, http: //www.ecologyandsociety.org/vol14/iss2/art32, 2009.

Rockström, J., Karlberg, L., Wani, S. P., Barron, J., Hatibie, N., Owas, Th., Bruggeman, A., Farahani, J., and Qiang, Z.: Managing water in rainfed agriculture. The need for a paradigm shift, Agr. Water Manage., 97, 543-550, 2010.

Schwilch, G., Hessel, R., and Verzandvoort, S. (Eds.): Desire for Greener Land. Options for Sustainable Land Management in Drylands, Bern, Switserland and Wageningen, the Netherlands, Univ. of Bern-CDE, Alterra-Wageningen-UR, ISRIC-World Soil Information and CTA-techn. Center for AGR and Rural Cooperation, 2012.

Smaling, E. M. A. and Bouma, J.: Bypass flow and leaching of nitrogen in a Kenyan Vertisol at the onset of the growing season, Soil Use Manage., 8, 44-48, 1992.

Smaling, E. M. A. and Janssen, B. H.: Calibration of QUEFTS, a model predicting nutrient uptake and yields from chemical soil fertility indices, Geoderma, 59, 21-44, 1993.

Smaling, E. M. A., Stein, A., and Sloot, P. H. M.: A statistical analysis of the influence of Striga hermonthica on maize yields in fertilizer trials in Southwestern Kenya, Plant Soil, 138, 1-8, 1991.

Smaling, E. M. A., Nandwa, S. M., Prestele, H., Roetter, R., and Muchena, F. N.: Yield response of maize to fertilizers and manure under different agro-ecological conditions in Kenya, Agr. Ecosyst. Environ., 41, 241-252, 1992.

Spaans, E., Bouma, J., Lansu, A., and Wielemaker, W. G.: Measuring soil hydraulic properties after clearing of tropical rain forest in a Costa Rican soil, Trop. Agr., 67, 61-65, 1990.

Spaans, E. J. A., Baltissen, G. A. M., Bouma, J., Miedema, R., Lansu, A.L.E., Schoonderbeek, D., and Wielemaker, W. G.: Changes in physical properties of young and old vulcanic surface soils in Costa Rica after clearing of tropical rain forest, Hydrol. Process., 3, 383-392, 1989.

Stein, A., Hoogerwerf, M., and Bouma, J.: Use of soil-map delineations to improve (co) kriging of point data on moisture deficits, Geoderma, 43, 163-177, 1988.

Stein, A., Brouwer, J., and Bouma, J.: Methods for comparing spatial variability patterns of millet, yield and soil data, Soil Sci. Soc. Am. J., 61, 861-870, 1997.
Stoorvogel, J. J., Kooistra, L., and Bouma, J.: Spatial and temporal variation in nematocide leaching, management implications for a Costa Rica banana plantation, in: Assessment of non-point source pollution in the vadose zone, Geophysical Monograph 108, Am. Geophys. Un., 281-289, 1999.

Stoorvogel, J. J., Bouma, J., and Orlich, R. A.: Participatory research for systems analysis: prototyping for a Costa Rican Banana Plantation, Agron. J., 96, 323-336, 2004.

Van Camp, L., Bujarrabal, B., Gentile, A. R., Jones, R. J. A., Montanarella, L., Olazabal, C., and S-Kumar Selvaradjou (Eds.): Reports of the TechnicalWorking Groups established under the Thematic Strategy for Soil Protection, EUR 2131'9EN/6, Office for the official publications of the European Commuinities, Luxembourg, 2004.

van Groenigen, J. W., Gandah, M., and Bouma, J.: Soil sampling strategies for precision agriculture research under Sahalian conditions, Soil Sci. Soc. Am. J., 64, 1674-1680, 2000.

van Ittersum, M. K., van Bussel, L. G. J., Wolf, J., Guilport, N., Claessens, L., de Groot, H., Wiebe, K., Mason-D’Croz, D., Yang, H., Boogaard, H., van Oort, P. A. J., van Loon, M. P., Saito, K., Adimo, O., Adjei-Nsiah, S., Agali, A., Bala, A., Chicowo, R., Kaizzi, K., Kouressy, M., Makoi, J. H. R., Ouatarra, K., Tesfaye, K., and Cassman, K. G.: Can Sub-Saheran Africa feed itself?, P. Natl. Acad. Sci. USA, 113, 14964-14969, https://doi.org/10.1073/pnas.1610359113, 2016.

Veldkamp, E., Huising, J. E., Stein, A., and Bouma, J.: Variability of measured banana yields in a Costarican plantation as expressed by soil survey and thematic mapper data, Geoderma, 47, 337$349,1990$.

Wopereis, M. S. C., Stein, A., Bouma, J., and Woodhead, T.: Sampling number and design for measurements of infiltration rates into puddled rice fields, Agr. Water Manage., 22, 281-295, 1992.

Wopereis, M. C. S., Kropff, M. J., Wösten, J. H. M., and Bouma, J.: Sampling strategies for measurement of soil hydraulic properties to predict rice yield using simulation models, Geoderma, 59, 120, 1993.

Wopereis, M. C. S., Bouma, J., Kropff, M. J., and Sanidad, W.: Reducing bypass flow through a cracked, previously puddled clay soil, Soil Till. Res., 29, 1-11, 1994.

World Bank: Agriculture for Development, The World Bank, Washington D.C., USA, 2008.

Wulf, A.: The invention of nature. The life of Alexander von Humboldt, John Murray Publ., London, UK, 2015. 